\title{
IMPACT RESPONSE Of PlATES UNDER DROP WEIGHT IMPACT TESTING
}

\author{
S. Elavenil and G.M. Samuel Knight \\ Dept of Civil Engineering \\ S.R.M.Institute of Science and Technology, Anna University, Tamilnadu, India \\ E-mail: s_elavenil@yahoo.com
}

\begin{abstract}
Concrete structures are often subjected to long term static and short term dynamic loads. Due to a relatively low tensile strength and energy dissipating characteristics, the impact resistance of concrete is poor. Research work carried out so far towards the development of concrete that exhibits improved impact resistance than conventional concrete showed that the steel fibre reinforced concrete has a good potential as a viable structural material for such applications. The overall objective of the study is to investigate the dynamic behaviour of steel fibre reinforced concrete plates under impact loading with respect to displacement, velocity and acceleration. In the drop weight test, eighteen plate specimens were tested with three different thicknesses of 20,25 and $30 \mathrm{~mm}$ and with three different steel fibre contents of 0.5,0.75 and 1\%.The edges of the plates were fixed on all sides. Displacement versus time, velocity versus time and acceleration versus time behaviour for all the plates tested were studied. It was found that when the aspect ratio of fibres is 50 and 75 there is a marginal increase in energy absorption for change in fibre content from 0.5 to $0.75 \%$. There is a steep increase in energy absorption for a steel fibre content of $1 \%$ when the aspect ratio of fibre is 100 .
\end{abstract}

Keywords: Dynamic response, energy absorption of the plate, steel fibres and plate specimens

\section{Introduction}

Current world events have clearly indicated that the need to protect civilian and military structures from terrorist or enemy attacks have never been greater. To minimize damage and to prevent collapse, these structures must posses a much greater resistance to impact loading. The understanding of the impact resistance of concrete and especially of high strength concrete is very limited. At the heart of the problem is the absence of a standardized test technique for testing concrete under impact. Many researchers have used different impact machines, specimen configurations, specimen sizes and instrumentations and have also adopted different analysis schemes. Much still remains to be done both towards the development of a standardized technique and towards generating fundamental understanding of the performance of concrete under impact loading.

Fibre composite materials in Civil Engineering were fairly limited until about ten years ago, when significant attention was made to these materials by Civil Engineers for repair and retrofit of structures. Because of the unique advantages of fibre composites, including corrosion resistance, high strength to weight ratio and versatility, they have been used in projects to strengthen steel, concrete, wood and masonry structures in the last several years. So far, most of the research conducted on composite applications have concentrated on static and pseudodynamic loadings. There are many situations in which structures undergo impact or dynamic loading, such as when there is an explosion, impact of ice load on pile structures, accidental falling loads, tornado generated projectiles. etc. The characteristics of impact load are different from those of static and seismic loads. Since the duration of loading is very short, the strain rate of material becomes significantly higher than that under static and seismic loading. Also, structural deformation and failure modes will be different from those under static and seismic loading.

Present day design codes are mainly based on the static method. Dynamic loads from earthquakes or accidental vehicular collisions are usually considered by introducing an equivalent dynamic load factor. Static design method would not adequately describe an impact phenomenon, as not only the maximum impulsive loading but 
also loading duration and loading rate have to be taken into account.

With increase in the awareness on the beneficial use of steel fibre reinforced concrete in place of conventional concrete for applications in structures, its use in India is likely to increase. Hence, it becomes necessary to investigate the salient features of the construction material. In conventional construction practice, compressive strength of concrete is often considered as an indicator of its quality whereas in the case of steel fibre reinforced concrete, specific tests are required to evaluate the impact resistance and flexural toughness.

Plates are commonly used structural elements and are subjected to wide variety of static and dynamic loads. Broadly the dynamic loads can be classified into three major categories

(i) Steady state harmonic loads as in the case of machine foundations and structures supporting rotating machines.

(ii) Random loads as in the case of seismic excitation on tall buildings, wind induced loads on slender structures or wave loads on offshore structures.

(iii) Impulsive or shock loads as in the case of missile impact, blast loads on structures, or an aircraft crashing against a civil engineering structure.

The term 'impact' covers a wide range of topics that are of great interest to do the research work. The dynamic response to impact is complex and is dependent on many factors such as velocity of the striker, size of the striker, contact area at the impact zone, size of the target structure, material behaviour of the target structure and the striker etc. A single test program involving all the above variables is not possible.

Thickness of the target structure is an important factor to avoid punching shear failures under high velocity impact. In certain civil engineering structures such as bridges, crusher supporting structures etc., the energy of a single impact as compared to their total energy absorption capacities are less. Also, the number of impact loads cycles are very large. Significant analysis of vibration record is also becoming popular for cumulative damage assessment of structural elements.
Impact loading results from a collision between two bodies wherein the load transfer occurs during a very small interval of time. Impact load on reinforced concrete walls and slabs are caused when they are accidentally hit by vehicles or flying objects or fragments during a heavy blast. Imapct loads become significantly important in the case of nuclear structures where the vulnerabilities of missile attack or accidental collision of an aircraft on the structure cannot be ignored. The response of the structure due to impact loading depends on the projectile mass, its velocity and the relative rigidities of the projectile and the structure. Where the structure is very rigid, the projectile undergoes extensive deformation and almost the entire kinetic energy is being transformed as deformations in the projectile. This impact is termed as 'soft impact'. When the is rigid, the energy of the striker is to a larger extent absorbed by the deformation in the structure and the process is termed as 'Hard Impact'. A transient dynamic analysis with a suitable mathematical model for the structure and striker accounting for the material nonlinearities and local damages is essential to obtain a reasonable non-linear dynamic response of the structure.

Impact loading has gained importance after the construction of nuclear power plants all over the world, as these structures are to be protected from bomb or rocket attack. The consequences of failure in such a situation are extremely high and therefore widespread intensive research on the impact behaviour of containment structures is in progress and the findings are regularly reported.

Nonlinear response of concrete beams and plates under impact loading was studied by Abbas et al (2004). The material model employed for reinforced concrete was capable of carrying out impact analysis and predict cracking and hence the extent of damage. The cracking strain was observed to be a sensitive parameter thus requiring its accurate estimation for the purpose of precise analysis. The results showed reasonably good agreement with experiments and also with those taken from literature.

Toughness characterisation of fibre reinforced concrete was studied by Taylor et al (1996). Cube strength, modulus of rupture, cylinder splitting and torsional tension test results were 
reported together with toughness measurements for polypropylene and steel fibre reinforced concrete. The toughness measurements were carried out with two fracture type test specimens. In the toughness tests, crack mouth opening displacement was measured and used in a closed loop testing mode to achieve complete load displacement curves. The result showed that the curves truely reflected the behaviour. The effect of fibre reinforcement on high strength and normal strength concrete were similar.

Flexural behaviour of steel fibre reinforced concrete beams under static load was studied by Balasubramanian et al (1998). Based on the experimental investigations conducted on the steel fibre reinforced concrete flexural beams under static loading, it was concluded that all the three types of fibres, viz., trough-shaped, crimped and straight, improved the flexural performance of reinforced concrete beams under static loading and the improvement increased with increase in percentage volume fraction of fibres. All the steel fibre reinforced concrete beams showed an increase of about 25\% in the first crack load over companion RC beams and the first crack load was not affected by the type of fibre.

Ong et al (1999) studied the resistance of fibre concrete slabs to low velocity projectile impact. The main variables of the study were type of fibre and volume fraction of fibres. The types of fibres chosen were polyolefin, polyvinyl alcohol and steel. The volume fraction of fibers examined were 0,1 and $2 \%$. A total of ten square slabs of size $1 \mathrm{~m}$ and $50 \mathrm{~mm}$ thickness were cast and tested. Impact was achieved by dropping projectile of mass of $4.30 \mathrm{~kg}$ from a height of $4 \mathrm{~m}$, by means of an instrumented impact test facility. It was concluded that steel fibre concrete slabs showed superior performance in terms of cracking characteristics, resistance to shear plug formation, energy absorption and integrity upon impact when compared to slabs reinforced with polyolefin and PVA fibres. Considering up to 20 $\mathrm{mm}$ displacement, at $0.5,1$ and $2 \%$ volume fraction of fibres the steel concrete slabs had about 40, 100 and 136\% higher fracture energy values, respectively, compared to polyolefin fibre concrete slabs, while about 19, 53 and 80\% higher fracture energy values respectively, compared to PVA fibre concrete slabs. It was also seen that the energy absorption capacities of PVA fibre concrete slabs were higher than polyolefin fibre concrete slabs for the same volume fraction. The slabs with $0.5,1$ and $2 \%$ volume fraction of PVA fibres has fracture energy higher by about 18, 31 and 31\% respectively, compared to polyolefin fibre concrete slabs.

Several investigations have employed a variety of tests to assess the impact resistance of concrete and fibre reinforced concrete. Four different methods that are reported in the literature to carry out impact tests are explosive test, projectile impact test, drop weight impact test and charpy impact test to study the impact behaviour of cementitious materials. However, till now, no standard methodology has emerged to assess the impact resistance of concrete. Blast and projectile impact tests are generally used to evaluate the impact resistance of structural members. However, these methods require special loading facilities to carry out the tests. Charpy impact test is employed for metals. American Concrete Institute has suggested the drop weight impact testing machine for steel fibre reinforced concrete and this is the simplest among all the four methods. The pendulum impact test results in quantitative estimate of the impact resistance of steel fibre reinforced concrete specimens. Therefore, this test method was selected and has been employed in the present investigation.

Table 1: Details of Fibres

\begin{tabular}{|c|c|c|}
\hline $\begin{array}{c}\text { Length } \\
(\mathrm{mm})\end{array}$ & $\begin{array}{c}\text { Diameter } \\
(\mathrm{mm})\end{array}$ & $\begin{array}{c}\text { Aspect Ratio } \\
\text { of Fibres }\end{array}$ \\
\hline 35.0 & 0.7 & 50 \\
\hline 52.5 & 0.7 & 75 \\
\hline 70.0 & 0.7 & 100 \\
\hline
\end{tabular}

\section{Experimental Investigation}

\subsection{Fabrication of Moulds and Test Set-up}

The plate element is cast in three different moulds each having fixed size of $600 \times 600 \mathrm{~mm}$ but thickness varying from $20 \mathrm{~mm}, 25 \mathrm{~mm}$ and $30 \mathrm{~mm}$. The mould is made with water proof and water tight plywood. The side of plywood 


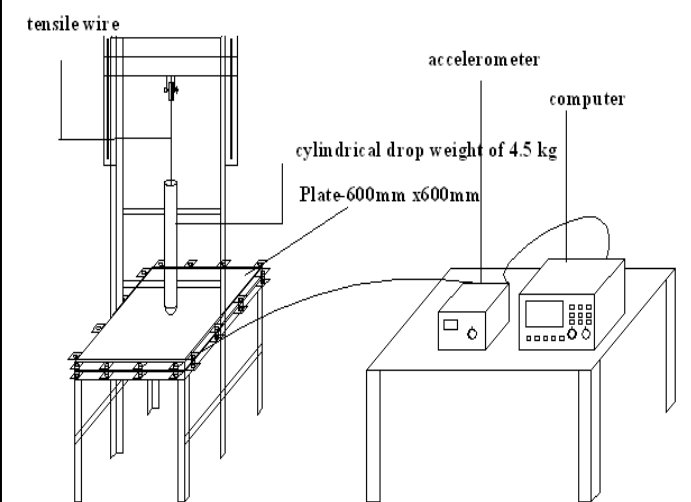

Fig. 1 (a): Drop Weight Impact Testing Machine

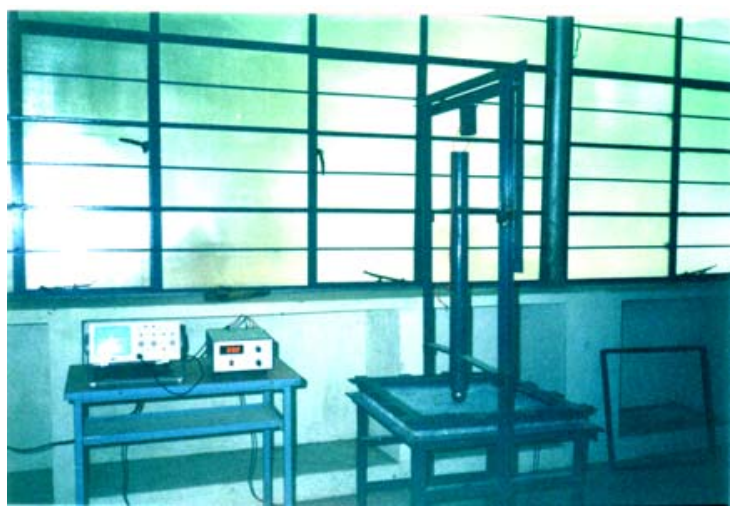

Fig. 1 (b): Drop Weight Impact Testing Machine

mould in the thickness side is bolted. The bolts are provided at corners and they are fastened. Before casting of the plate elements, the moulds and the fastening bolts are properly cleaned and applied with one coat of wax oil as mould releasing agent to get better surface finish.

\subsection{Preparation of Fibre}

The diameter of the fibre taken for the investigation on dynamic response of FRC plates is $0.7 \mathrm{~mm}$. The fibres are available in market in continuous length, but the experiment requires three different aspect ratios. The conveniently available fibres of $0.7 \mathrm{~mm}$ diameter were purchased and it was cut by using sheet cutting instrument. The details of the fibres chosen is given in Table 1.

\subsection{Material and Mix Proportion}

Cement concrete is a composite material comprises of cement, fine aggregate, coarse aggregate and water. Concrete is made with several types of cement and also contains pozzolona, fly ash, blast furnace slag, sulphur, admixtures, polymers, fibres etc., and concrete can be heated, steam cured, autoclaved, vacuum treated, hydraulically pressed, shock vibrated, extruded and sprayed. The designer specifies the required properties of hardened concrete and the properties of fresh concrete are governed by the type of construction and by the techniques of placing and transporting. These requirements make it possible to determine the composition of the mix, taking into account the degree of control exercised at site.

The materials used in the preparation of test specimens are ordinary Portland cement of grade 53 conforming to IS : 12269 1987 , locally available river sand passing through IS sieve $2.36 \mathrm{~mm}$, crushed blue granite aggregates passing through $10 \mathrm{~mm}$ sieve and steel fibre of diameter $0.7 \mathrm{~mm}$ having aspect ratios of 50, 75 and 100 . The fibre content (percentage by volume) used are 0.5,0.75 and 1.0\%. Mix design was done according to IS : 10262 and the mix proportion for all the specimens is kept the same as 1:1.22: 11.91 by weight of cement, fine and coarse aggregates. The preliminary free water cement ratio is $0.5 \%$. For durability requirements, the maximum water cement ratio for severe exposure is taken as 0.45 according to IS : 456 - 2000. The same water cement ratio is maintained for the mix design.

\subsection{Testing of the Specimen}

The drop weight testing arrangement used in this investigation is shown in Fig. 1. The equipment consists of a stainless steel ball of $61.5 \mathrm{~mm}$ weighing $0.5 \mathrm{~kg}$ and a cylindrical drop weight of $4.5 \mathrm{~kg}$ which is connected to a tensile wire that can be manually controlled, which is kept vertically by a steel wire fixed to the frame. The inside surface of the steel tube is lubricated to prevent any friction between the ball and the casing. The whole arrangement is fixed to a vertical steel frame which is welded to the base frame which holds the slab. A square annular frame of inner dimension $600 \times 600 \mathrm{~mm}$ and outer dimension 640 × $640 \mathrm{~mm}, 20 \mathrm{~mm}$ thick, enables fixity to the slab along the edges and 


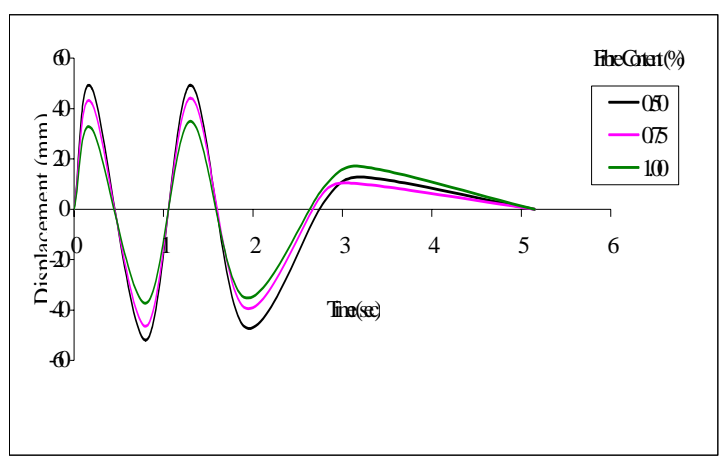

Fig. 2(a): For 20 mm Thick Plate

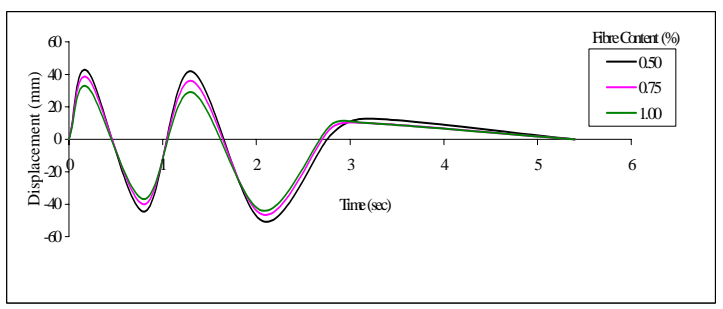

Fig. 2(b): For 25 mm Thick Plate holds the slab horizontally. The height of fall of the spherical ball is kept constant for all the experiments i.e $750 \mathrm{~mm}$. The number of drops (blows) required for first cracking of the slab is noted. The cracks were measured using a Brinell microscope, which has an accuracy of $0.1 \mathrm{~mm}$. A small iron square size plate of $20 \mathrm{~mm} \times 20 \mathrm{~mm}$ is placed under the centre of the plate while casting the plate, to pick-up the impact effect. The pick up leads to the accelerometer and then to the computer. The displacement time history, velocity time history, acceleration time history and crack widths were recorded.

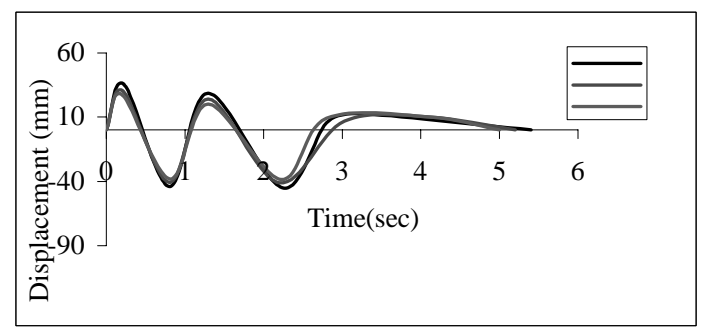

Fig. 7(r): For $30 \mathrm{~mm}$ Thirk Plate

Fig. 2 (a) to (c): Displacement versus Time Behaviour of SFRC Plates -4 sides fixed - Drop Weight Impact Test for $\mathrm{l} / \mathrm{d}=100$

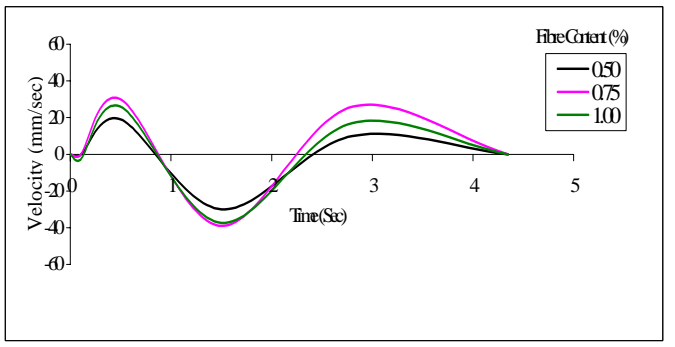

Fig. 3(a): For $20 \mathrm{~mm}$ Thick Plate

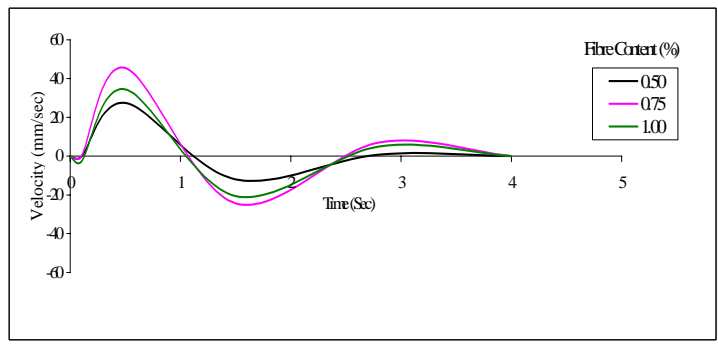

Fig. 3(b): For 25 mm Thick Plate
The support condition used here is all around fixed and all around simply supported. For the simply supported condition the setup is arranged in such a way that the plate of $40 \mathrm{~mm}$ width is welded to a rod of $12 \mathrm{~mm}$ diameter in a square shape and the center to center length is $600 \mathrm{~mm}$. The fixed support condition is provided by a plate with a thickness of $10 \mathrm{~mm}$ and which fit exactly inside the frame for supporting the concrete plate. The support condition is provided in such a way that the support will be given both

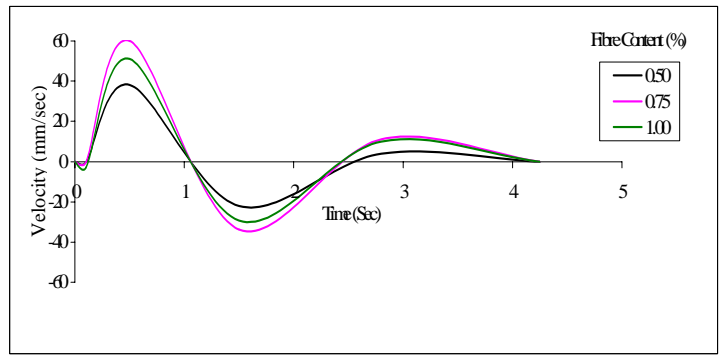

Fig. 3(c): For $30 \mathrm{~mm}$ Thick Plate

Fig. 3: Velocity versus Time Behaviour of SFRC Plates-4 sides fixed - Drop weight Impact Test for $1 / \mathrm{d}=100$ 
at top and bottom of the horizontal plate. The specimen is clamped all around by bolts to have the proper support condition. The concrete plates are prepared in such a way that there is a square plate placed under the concrete plate to fix the accelerometer to the plate.

From the Drop weight impact tests, the following characteristics are discussed.

- Displacement, velocity, acceleration versus time behaviour for different thicknesses of plates.

- Comparison of Energy absorbed at first crack and at failure for different steel fibre contents and aspect ratios of fibres

- Number of blows versus fibre contents behaviour

\subsection{Displacement versus Time Behaviour of Plates}

Fig. 2 (a) to (c) show the displacement versus time behaviour for steel fibre reinforced concrete plates fixed on four sides for three different thicknesses and three different steel fibre contents. It can be seen that the displacements are maximum at 0.5 seconds irrespective of the thickness of the plates. The behaviour is similar for all the plates with different steel fibre contents. The maximum displacement is nearly $50 \mathrm{~mm}$ for $0.5 \%$ as compared to $1 \%$ for $20 \mathrm{~mm}$ thickness of the plate and $40 \mathrm{~mm}$ for $25 \mathrm{~mm}$ thickness of plates and $35 \mathrm{~mm}$ for $30 \mathrm{~mm}$ thickness of plates. The

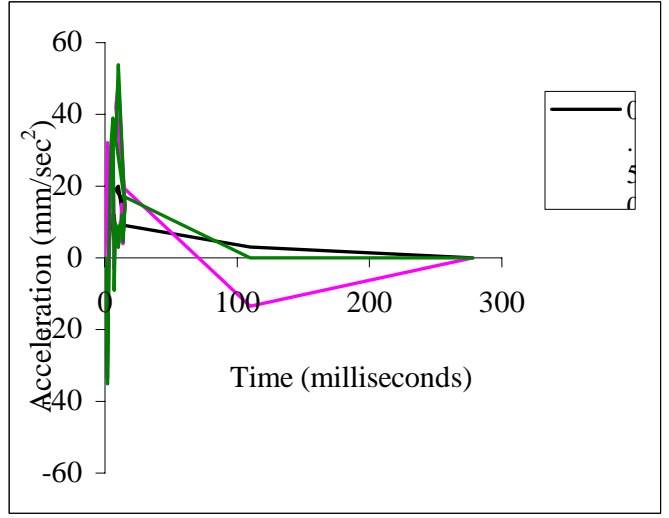

Fig. 4(b): For 25 Thick Plate displacements become zero at the end of 5 seconds for plates of all thicknesses and fibre contents.

\subsection{Velocity versus Time Behaviour of Plates}

Fig. 3 (a) to (c) show the velocity versus time behaviour for steel fibre reinforced concrete plates fixed on four sides for three different thicknesses and three different steel fibre contents. The behaviour is similar for all the thicknesses of plates and also for all steel fibre contents. Maximum velocity has occurred at 0.5 seconds for all the plates. The effect of steel fibre content is significant for plates of

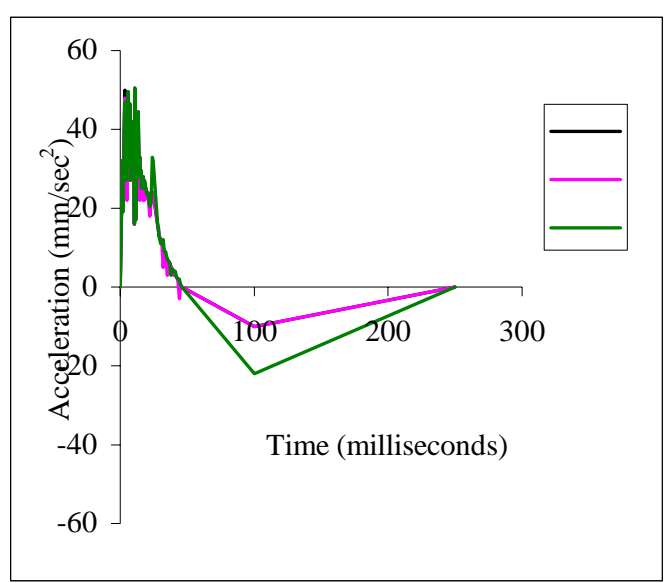

Fig. 4(a): For 20 Thick Plate

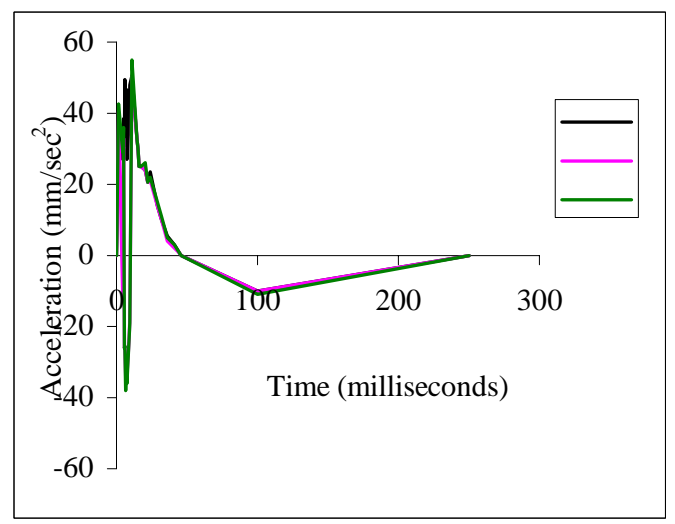

Fig. 4(c): For 30 Thick Plate

Fig. 4 : Acceleration versus Time Behaviour of SFRC Flates - 4 sides fixed - Drop Weight Impact Test for $\mathrm{l} / \mathrm{d}=100$ 
thickness $25 \mathrm{~mm}$ and $30 \mathrm{~mm}$. The velocity becomes nil at 4 seconds for all the plates.

\subsection{Acceleration versus Time Behaviour of Plates}

Fig. 4 show the acceleration versus time behaviour of steel fibre reinforced concrete plates fixed on four sides for three different thicknesses and three different steel fibre contents. Peak acceleration occurred at 10 milliseconds irrespective of the thickness of the plates. The change in steel fibre content has not shown any significant change in the behaviour.

\section{Energy Absorption}

Table 2 gives the Energy absorbed at first crack and at failure for three different aspect ratios of fibres and three different steel fibre contents. Calculation of energy absorbed is from the load displacement curves.

Table 2: Energy Absorbed at first crack and at failure

\begin{tabular}{|c|c|c|c|c|}
\hline $\begin{array}{c}\text { Sl.No } \\
\text {. }\end{array}$ & $\begin{array}{l}\text { Aspect ratio of fibre } \\
(\mathrm{l} / \mathrm{d})\end{array}$ & Fibre Content (\%) & $\begin{array}{l}\text { Energy First Crack } \\
\left(\mathrm{Nmm} \times 10^{3}\right)\end{array}$ & $\begin{array}{c}\text { Energy at Failure } \\
\left(\mathrm{Nmm} \times 10^{3}\right)\end{array}$ \\
\hline 1 & \multirow{3}{*}{50} & 0.5 & 50 & 440 \\
\hline 2 & & 0.75 & 55 & 450 \\
\hline 3 & & 1.00 & 65 & 580 \\
\hline 4 & \multirow{3}{*}{75} & 0.5 & 66 & 460 \\
\hline 5 & & 0.75 & 69 & 660 \\
\hline 6 & & 1.00 & 70 & 860 \\
\hline 7 & \multirow{3}{*}{100} & 0.5 & 104 & 775 \\
\hline 8 & & 0.75 & 155 & 875 \\
\hline 9 & & 1.00 & 200 & 900 \\
\hline
\end{tabular}

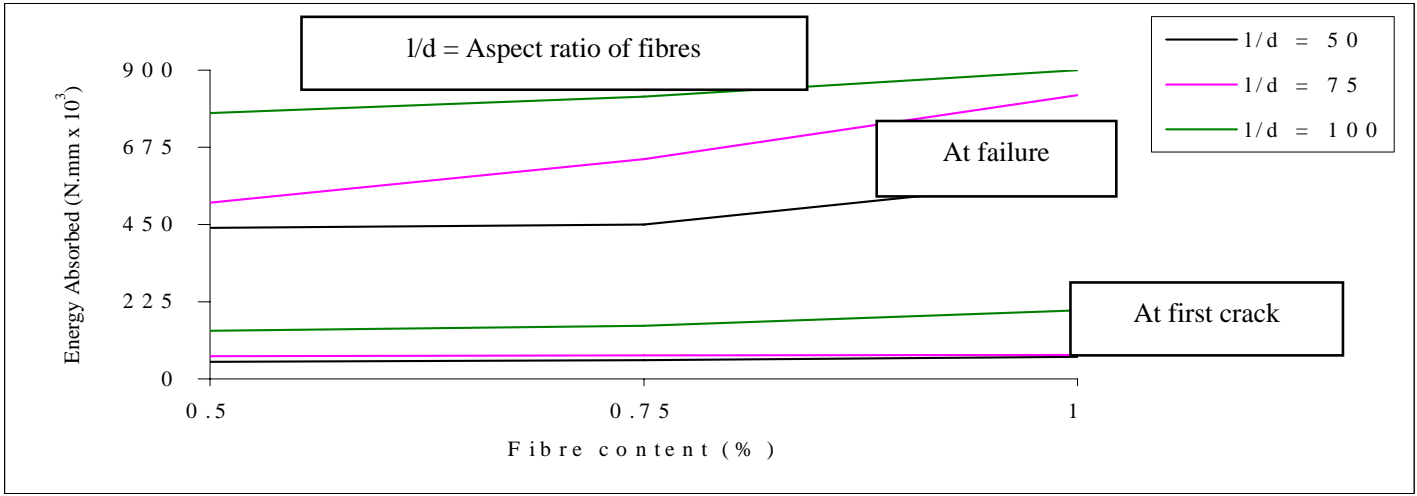

Fig. 5: Energy Absorbed versus Fibre Content

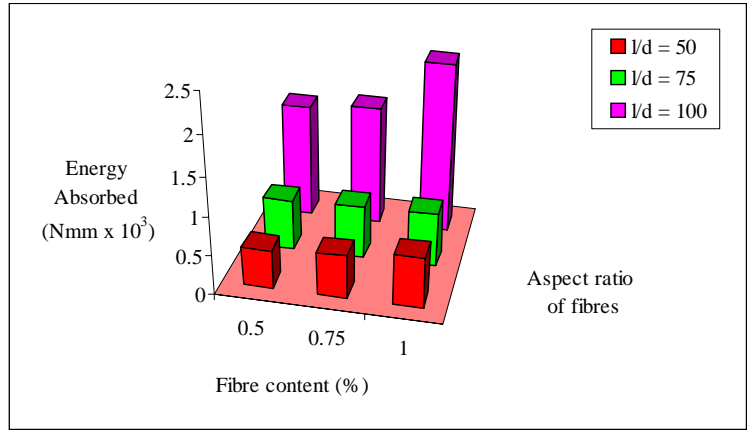

Fig. 6(a): Energy Absorption at First Crack

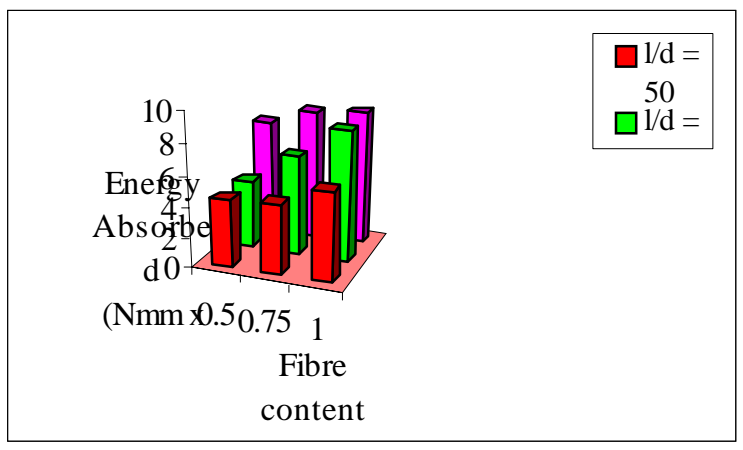

Fig. 6(b): Energy Absorption at Failure Crack

Fig. 6: Comparison of Energy Absorption for SFRC Plates 


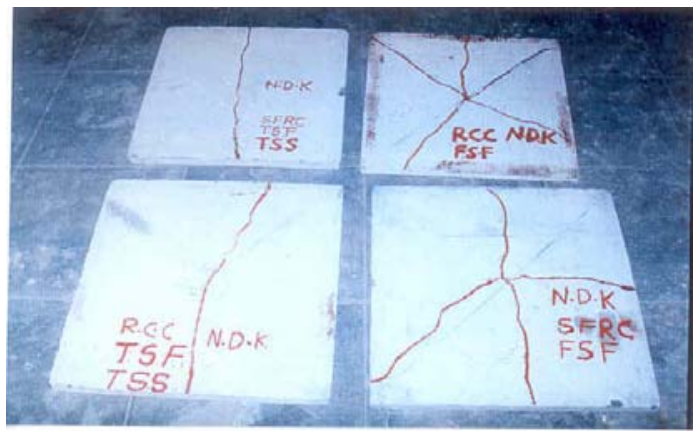

Fig. 7: Cracking Pattern of Plates

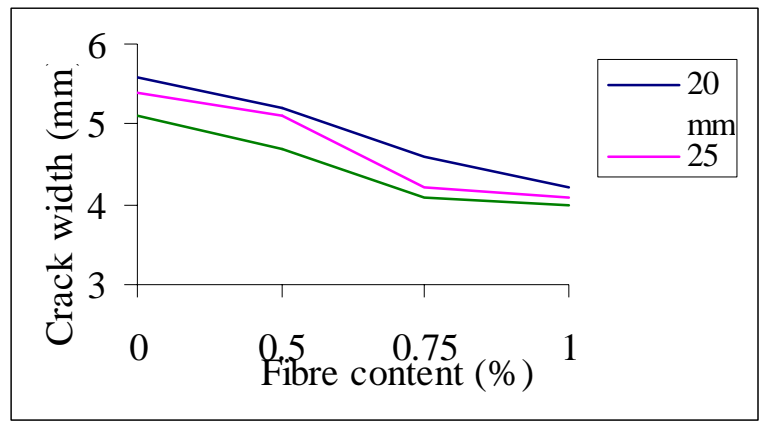

Fig. 8(a): For $1 / \mathrm{d}=50$

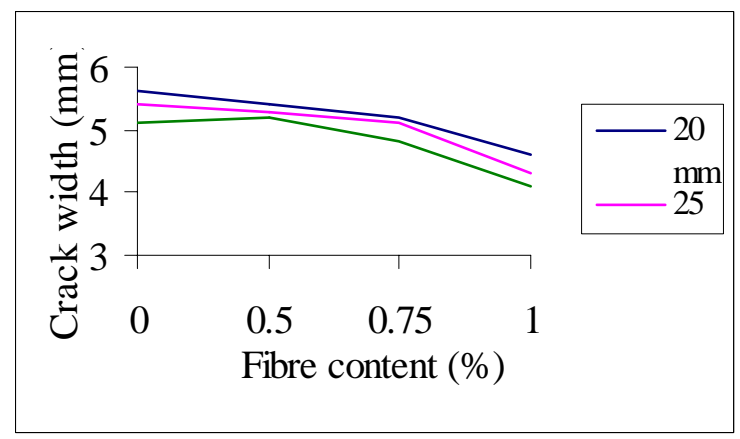

Fig. 8(b): For $1 / \mathrm{d}=75$
The specimens which appear to possess relatively low impact resistance at first cracking have been found to be weak in impact resistance at failure. Randomly distributed steel fibres in concrete matrix offer resistance to development and propagation of cracks in the post cracking regime of concrete. This aspect is reflected in the high impact resistance of steel fibre reinforced concrete specimens at failure. The comparison of energy absorbed at first crack and at failure is shown in Fig. 6(a) and

\subsection{Impact Resistance}

The number of blows versus steel fibre content behaviour of plates for different thicknesses of plates, different steel fibre contents and aspect ratio of steel fibres are measured. The behaviour is similar for the three different thickness of plates. There is drastic increase in the number of blows when the fibre content is increased from $0.75 \%$ to $1 \%$. Aspect ratio of steel fibres does not play a significant role in the behaviour when the fibre content is less than $0.5 \%$. It can be also seen that the impact strength in increased substantially by increasing the fibre content and

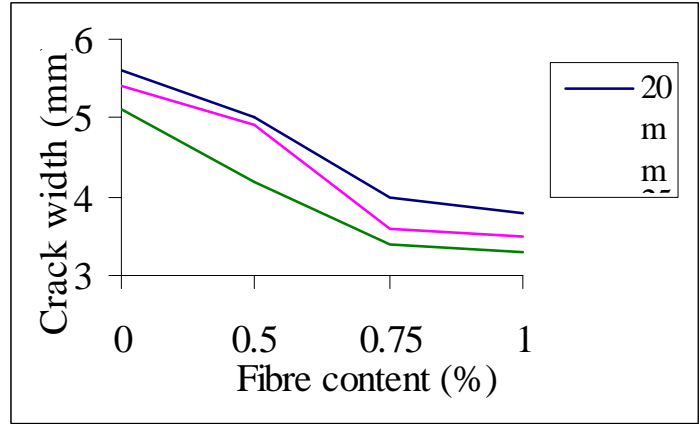

Fig. 8(c): For $1 / \mathrm{d}=100$

Fig. 8 : Crack width versus Fibre Content Behaviour of SFRC plates

Fig. 5 shows the energy absorbed versus fibre content behaviour. It can be seen that the behaviour is almost linear upto the first crack. At failure two distinctly different behaviour are noticed. When the aspect ratio of steel fibres is 50 and 75 there is a marginal increase in energy absorption for change in fibre content from 0.5 to $0.75 \%$ and then there is a steep increase for a fibre content of $1 \%$ when the aspect ratio of fibre is 100 , the behaviour is almost linear. steel fibre length.

\subsection{Cracking Pattern of Plates}

The Fig. 7 shows the crack pattern of steel fibre reinforced concrete plates with fixed edges on two sides. Plates with two opposite sides fixed show cracks propagating parallel to the support and plates with four edges support show radiating cracks.

Fig. 8(a) to (c) show the variation of crack width of steel fibre reinforced plates for different fibre contents and plate thicknesses. It can be seen that irrespective of thicknesses of plates, there is a 
decrease in crack width for increase in steel fibre contents. There is a sudden decrease in crack width when the aspect ratio of fibres is 75 and 100. The decrease is gradual when the aspect ratio of fibres is 50. Crack widths are marginally higher of the order of $10 \%$ for $20 \mathrm{~mm}$ plates as compared to $30 \mathrm{~mm}$ plates, irrespective of whether the steel fibre content is 0.5 or $1 \%$. When the aspect ratio of fibres is 100 , crack widths reduce by $50 \%$ for $1 \%$ addition of steel fibre content.

\section{Conclusion}

The dynamic response of steel fibre reinforced concrete plates under impact loading using the drop weight test was studied. Three different aspect ratios of steel fibres and three different steel fibre contents with four sides fixed end condition was chosen. Acceleration versus time, displacement versus time, velocity versus time behaviour of the plates was studied. The stiffness of the plates and also the energy absorbed were also evaluated and compared. Based on the experimental investigations conducted the following conclusions are drawn. The maximum displacement is nearly $50 \mathrm{~mm}$ for $0.5 \%$ as compared to $1 \%$ for $20 \mathrm{~mm}$ thickness of the plate and $40 \mathrm{~mm}$ for $25 \mathrm{~mm}$ thickness of plates and $35 \mathrm{~mm}$ for $30 \mathrm{~mm}$ thickness of plates. The displacements become zero at the end of 5 seconds for plates of all thicknesses and steel fibre contents.

Maximum velocity occurs at 0.5 seconds for all the plates. The effect of fibre content is significant for plates of thickness 25 and 30 $\mathrm{mm}$. The velocities become zero at 4 seconds for all the plates.

Peak acceleration occurs at 10 milliseconds for all the plates irrespective of the thickness of the plates. The change in fibre content does not show any significant change in the behaviour.

i. The Peak Acceleration of the Steel Fiber of Volume fraction $1 \%$ of $25 \mathrm{~mm}$ thick slab was more then the Peak Acceleration of the Polypropylene Fiber of Volume fraction $0.1 \%$ of $25 \mathrm{~mm}$ thick for simply Fixed condition.

ii. The Peak Velocity of the Steel Fiber of Volume fraction $0.75 \%$ of $25 \mathrm{~mm}$ thick slab was more then the Peak Velocity of the Polypropylene Fiber of Volume fraction $0.1 \%$ of $20 \mathrm{~mm}$ thick for simply Fixed condition.

iii. The Maximum Displacement \& Minimum Displacement of the Polypropylene Fiber of Volume fraction $0.2 \%$ of $20 \mathrm{~mm}, 0.1 \%$ \& $20 \mathrm{~mm}$ thick slab was more then the Maximum Displacement \& Minimum Displacement of the Steel Fiber of Volume fraction 1\% of $30 \mathrm{~mm}, 0.75 \%$ \& $30 \mathrm{~mm}$ thick for Fixed support condition. Comparing with the work carried with the literature made with polypropylene fibre

- When the aspect ratio of fibres is 50 and 75 20\% increase in energy absorption for change in fibre content from 0.5 to $0.75 \%$. The increase in the energy absorption is $50 \%$ for a steel fibre content of $1 \%$ when the aspect ratio of fibre is 100.

- The plates which appear to possess relatively low impact resistance at first cracking are found to be weak in impact resistance at failure. Randomly distributed steel fibres in concrete offered resistance to development and propagation of cracks in the post cracking regime of concrete.

- $50 \%$ increase in the number of blows to failure when the steel fibre content is increased from $0.75 \%$ to $1 \%$. Fibre aspect ratio does not play a significant role in the behaviour when the steel fibre content is less than $0.5 \%$ but when the steel fibre content is increased to $0.75 \%$ and $1 \% 60 \%$ increase in the impact strength is achieved

- The crack width in steel fibre reinforced concrete plates is much less as compared to cracks in plates without steel fibres. The reduction in crack width is directly proportional to increase in fibre content. The maximum crack width at failure also decreased with the increase in steel fibre content.

- There is a decrease in crack width for increase in steel fibre contents. The rate of decrease of crack width is higher for the aspect ratio of fibres 75 and 100 . 


\section{References}

[1] Abbas H., Gupta N.K and Alam M (2004), “Non Linear Response of Concrete Beams and Plates Under Impact Loading”, International Journal of Impact Engineering, Vol.30, pp. 1039 - 1053.

[2] K. Anbuvelan, A Study on properties of High Strength Concrete containing polypropylene fibers International Conference on IWC 2003, Pune, India, September 2003, PP.11-12.

[3] Atef Badr and Ashraf Ashour F. (2005), "Modified ACI Drop - Weight Impact Test For Concrete”, ACI Material Journal, Vol.102, No.4, pp. 249 - 255.

[4] Ayaho Miyamoto., Michael W. King and Manabu Fujii (1991), "Non Linear Dynamic Analysis of Reinforced Concrete Slabs Under Impulsive Loads”, ACI Structural Journal, Vol.88, No.4, pp. 411 - 419.

[5] Balasubramanian K., Bharatkumar B.H., Gopalakrishnan S and Parameswaran V.S (1998), "Flexural Behaviour of Steel Fibre Reinforced Concrete Beams Under Static Load”, Journal of Structural Engineering, Vol.25, No.3, pp.167 - 172.

[6] Balasubramanian K., Bharatkumar B.H., Gopalakrishnan S and Parameswaran V.S (1996), "Impact Resistance of Steel Fibre Reinforced Concrete”, The Indian Concrete Journal, Vol.24, No.3, pp. 257 - 261.

[7] Glovanni Belingardi and Roberto Vadori (2003), "Influence of the Laminate Thickness in Low Velocity Impact Behaviour of Composite Plate”, Composite Structures, Vol.61 pp. 27 -38.

[8] Bhat R.B., Laura P.A.A., Gutierrez R.G and Cortinez V.H (1990), "Numerical Experiments on the Determination of Natural Frequencies of Transverse Vibrations of Rectangular Plates of Non - Uniform Thickness", Journal of Sound and Vibration, Vol.138, No.2, pp. 205 - 219.

[9] Bindiganavile V and Banthia N (2001), "Polymer and Steel Fibre Reinforced Cementitious Composites Under Impact Loading - Part 1: Bond - Slip Response ”, ACI Materials Journal, Vol.98, No.1, pp. 10 - 23.

[10] Bin Mu and Christian Meyer (2003), "Bending and Punching Shear Strength of Fibre Reinforced Glass Concrete Slabs”, ACI Materials Journal Vol.100, No.2, pp. 127 - 132.

[11] Craig M., Newtson and Marc O. Eberhard (2000), "Nondestructive Evaluation Using Numerical Simulation of Impact Response”, ACI Material Journal, Vol.97, No.3, pp. 343 - 350.

[12] Davies, G.A.O., Hitchings D., Besant T., Clarke, A and Morgan, C. (2004), "Compression after Impact Strength of Composite Sandwich Panels”, Composite Structures, Vol.63, pp. 1 - 9.

[13] Dawe D.J and Wang S (1994) "Buckling of Composite Plates and Plate Structures Using the
Spline Finite Strip Method”, Composite Engineering, Vol.4, No.11, pp. 1099 - 1117.

[14] Deolasi P.J., Datta. P.K and Prabhakara D.L (1995), "Buckling and Vibration of ectangular Plates Subjected to Partial Edge Loading”, Journal of Structural Engineering, Vol.22, No.3, pp.135 - 144.

[15] Ercoli L., Laura P.A.A and Gil R (1990), "Fundamental Frequency of Vibration of Rectangular Plates of Discontinuously Varying Thickness with a Free Edge: Analytical and Experimental Results”, Journal of Sound and Vibration, Vol.141, No.2, pp. 221 -229.

[16] Erki M.A., and Meir U (1999), “Impact Loading of Concrete Beams Externally Strengthened with CFRP Laminates", Journal of Composites for Construction, Vol.3, No.3 pp.117 - 124.

[17] Findik F and Tarim N (2003), "Ballistic Impact Efficiency of Polymer Composites”, Composite Structures, Vol.61, pp. 187 - 192.

[18] Gajbir Singh., Kanaka Raju K., Venkateswara Rao G (1990), "Non Linear Vibrations of Simply Supported Rectangular Cross - Ply Plates”, Journal of Sound and Vibration, Vol.142, No.2, pp. 213 - 226.

[19] Gorman D.J and Wei Ding (2003), “Accurate Free Vibration Analysis of Completely Free Symmetric Cross - Ply Rectangular Laminated Plates", Composite Structures, Vol.60, pp. 359 - 365.

[20] Han L. H, Zhao X. L. and Tao Z (2001), “Tests and Mechanics Model for Concrete-filled SHS Stub Columns, Columns and Beam-Columns”, Steel and Composite Structures, Vol.1, No.1, pp.51-74.

[21] Humayun R. H. Kabir (2004), "Free Vibration Response and Mode Shapes of Arbitrarily Laminated Rectangular Plates”, Composite Structures, Vol.65 pp. 13 - 27.

[22] Jun Deng., Marcus M.K., Lee and Stuart S.J. Moy (2004), "Stress Analysis of Steel Beams Reinforced with a bonded CFRP Plate”, Composite Structures, Vol.65, pp. 205 - 215.

[23] Kobayashi H and Sonoda K (1991), "Vibration and Buckling of Tapered Rectangular Plates with Two Opposite Edges Simply Supported and the other Two Edges Elastically Restrained Against Rotation”, Journal of Sound and Vibration, Vol.146, No.2, pp. $323-337$.

[24] Krishnamoorthy T. S., Bharatkumar B. H., Balasubramanian and Gopalakrishnan S (2000), "Investigations on Durability Characteristics of SFRC”, The Indian Concrete Journal, pp. 94 - 98.

[25] Li., Jian Bao Li., and Rou Qi Zhang (2004), "Energy - Absorption Performance of Porous Materials in Sandwitch Composites Under Hypervelocity Impact ling”, Composite Structures, Vol .64, pp. $71-78$. 
[26] Lin Z.C and Ho C.Y (1991), “An Investigation of Elastic Impact Problems on Beams and Plates”, Journal of Sound and Vibration, Vol. 148, No.2, pp. 293 -306.

[27] T aylor M.R., Lydon F.D. and Barr B.I.G. (1996), "Toughness Characterisation of Fibre Reinforced Concrete”, The Indian Concrete Journal, Vol.56, No.3 pp. 525 - 531.

[28] Ong K.C.G., Basheerkhan M. and Paramasivam P. (1999), "Resistance of Fibre Concrete Slabs to Low Velocity Projectile Impact”, Cement and Concrete Composites, Vol.21, pp. 391 - 401.

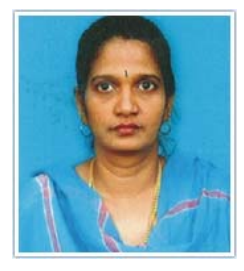

Dr. S. Elavenil is a Professor of Department of Civil Engineering, SRM University, Kattankulathur, Chennai-600 113, India. She has earned her B.E. degree from the Madurai Kamaraj University in Civil Engineering in 1988 and M.E. degree from the Bharathidasan University in Structural Engineering in 1994. She also achieved Ph.D. degree from the Anna University, India in "Dynamic response of plates under impact loading" in 2006. She had published many papers in national and International Journals. She has participated in several National and International Conferences for presenting her research papers. 